\title{
Computer Aided System for Crankshafts Failure Rate of Automobile Based on Distance Travel and Age
}

\author{
Yakubu Anakobe Jimoh'1, Buliaminu Kareem², Akinnuli Basil Olufemi² \\ ${ }^{1}$ Department of Computer Engineering, Federal Polytechnic, Ile-Oluji, Nigeria \\ ${ }^{2}$ Department of Mechanical Engineering, Federal University of Technology, Akure, Nigeria \\ Email: yakubqiblah@yahoo.com, ifembola@yahoo.com
}

How to cite this paper: Jimoh, Y.A., Kareem, B. and Olufemi, A.B. (2018) Computer Aided System for Crankshafts Failure Rate of Automobile Based on Distance Travel and Age. Open Access Library Journal, 5: e4134.

https://doi.org/10.4236/oalib.1104134

Received: November 8, 2017

Accepted: January 8, 2018

Published: January 11, 2018

Copyright $\odot 2018$ by authors and Open Access Library Inc.

This work is licensed under the Creative Commons Attribution International License (CC BY 4.0).

http://creativecommons.org/licenses/by/4.0/

\begin{abstract}
The crankshaft is the part of an engine which translates reciprocating linear piston motion into rotation. Automobile crankshaft failure, apart from poor maintenance culture, is caused by age and distance covered. These attributes which caused crankshaft failure were investigated using questionnaire administration and oral interviews of the maintenance expert and experienced personnel in the three selected crankshaft maintenance shops in Akure, Nigeria based on six popular crankshaft brands. Information/data on failure rate and failure consequence thresholds were established and served as a decision rule on the basis at which optimal reconditioning process, replacement and interchangeability system of the crankshaft components were identified on the occurrence of failure rate $\left(\mathrm{R}^{1}\right)$ and failure consequence $\left(\beta^{1}\right)$. Computer algorithm was developed for the software package, using Microsoft Visual C\# computer language. The software was tested to determine their level of performance. The results generated from the application of these systems were categorised into six scenarios whereby the MC230 Class gave the best result. The software will be veritable tools in predicting crankshaft failure in automobile, manufacturing, and machine tools industries, for prompt solution.
\end{abstract}

\section{Subject Areas \\ Computer Engineering}

\section{Keywords}

Automobile Crankshafts, Modelling, Failure Rate, Distance Travel and Age 


\section{Introduction}

Improved performance of the transportation sector therefore, will have positive effects on the national economy [1]. The heart of an automotive vehicular system is the crankshaft because vehicular movement would seize if it fails [2]. Automobile crankshaft failures and their associated problems have increased with the developments in automotive industries as many brands/models of vehicles are on sales in recent time [2]. The failure of crankshaft is a very severe problem faced by engineers recently. While some engineers belief that most of the failure are due to fatigue failure, other belief it that failure is beyond Fatigue. These include crankshaft installation, configuration and location [3] [4] and [5]. Increase in crankshaft failure was attributed to rapid increase in car ownership, low expansion rate of roads, and poor engine maintenance culture [2]. Failure modelling of crankshaft has been dealt with by many researchers [5] [6] [7]. However, many of these efforts failed to consider practical aspect of failure rate modeling failure rate by considering distance travelled and age. In this study, the automobile crankshaft failure rate is modeled based on distance travel and age. The outcomes are used to predict failures of different brands of crankshafts in order to prevent any premature failure [8]. Figure 1 shows typical example of vehicular crankshaft.

Crankshafts are manufactured with different materials and during its operation, due to cyclic loadings, cracks are produced on its surface, ultimately resulting into failure of crankshaft due to vibration [4] [9]. This study used expert's information/data obtained from well-established maintenance job-shops to model the crankshaft failure under distance travel and age with the assumption that the causes of failure are random and the failure itself is randomly occurred that magnitudes are different over the years. Section 2 presents literature review on critical causes/modes of failure on crankshaft to warrant this study,

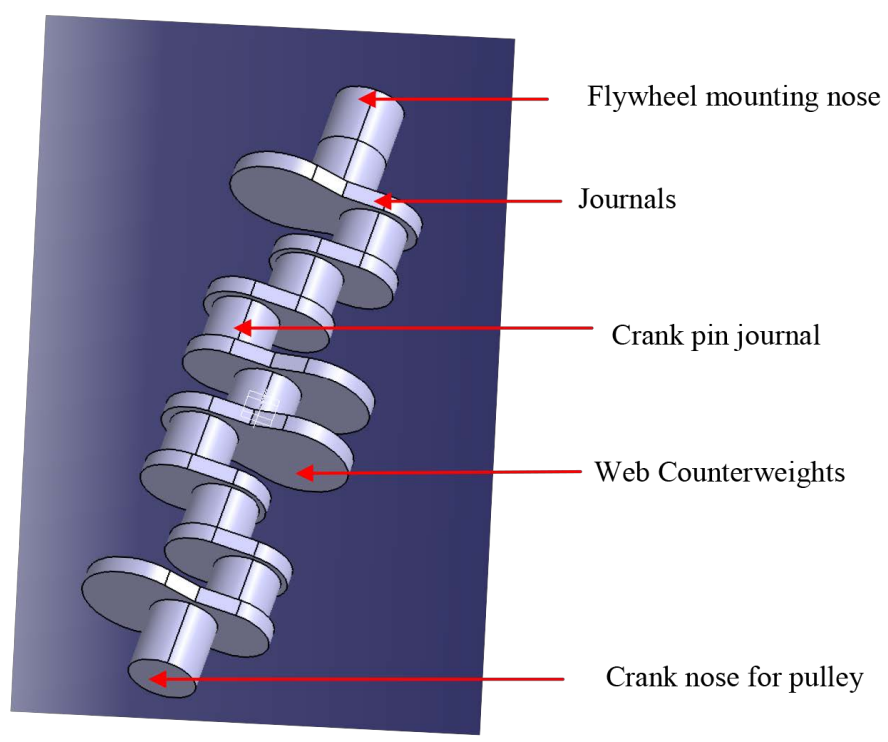

Figure 1. Vehicular crankshaft. 
research methodology including modelling criteria is presented in Section 3. Section 4 presents results and discussion; and conclusion \& reference sections end this paper.

\section{Literature Review}

\section{Review on Crankshaft Failures}

[10] investigated the crack produced in the two crankshafts of diesel van which were used for $30,000 \mathrm{~km}$ and then grinding is done. After machining both the crankshafts lasted only for $1000 \mathrm{~km}$ and resulting into the Journal damage.

[11] studied 4-Cylinder reciprocating compressor used in bus climate control system. [12] studied failure of 4-stoke $18 \mathrm{~V}$ diesel generator crankshaft used in electrical power plant. [8] presented a Low cycle fatigue (LCF) tests which were carried out on forged carbon steel (AISI 4130) used in V12 Diesel engine crankshafts, at room temperature and $300^{\circ} \mathrm{C}$, under total strain control.

[13] worked on finding out the causes of failure of aircraft engine crankshaft. The research was oriented about the failure of the crankpin journal due to fatigue. [14] investigate and discuss the method of assessment of the grinding wheel cutting ability in the plunge grinding of crankshaft. [15] worked and find out the technical developments in crankshaft failure. [16] carries out the investigation of the failure of three different crankshafts of 12 cylinders V-12 design engine used in trains. [17] worked on finding out the causes of failure of transport aircraft crankshaft. The failure is due to rubbing action between journal and bearing due to axial load on the shaft. [18] investigation of crankshaft made up of forged carbon steel resulting into premature failure in the web regions.

[19] undergone fatigue failure analysis of cast iron crankshaft and area where bending is occurred is studied, along with residual stresses produced due to fillet rolling process. [20] carries out the analysis of the crankshaft which failed in a strange manner when it was under testing only for $20 \mathrm{~min}$. [21] presented work for the effect of presence of slant crack in the crankpin of crankshaft and a model for vibration analysis is developed. [22] presented his work on the single cylinder diesel engine crankshaft used in the agricultural vehicles.

[23] investigated a failure analysis of two damaged crankshafts are presented: one obtained from a diesel engine of a mini backhoe, and another one from an automobile vehicle. [24] investigated the effect of fillet rolling on the fatigue behaviour of the ductile cast iron crankshaft used in diesel engines. [25] used ductile crankshaft which is commonly used for lightweight truck. Other factors affecting crankshaft failure of motor vehicle are: Age/length of usage, mileage/ extent of usage, condition of engine/transmission, body condition, tire condition, maintenance history and functionality of accessories [2] [26].

\section{Methodology}

\subsection{The Method Used Covered Vehicular Brands/Models}

The six brands/models of vehicles covered in this research are designated as TC, 
HC, MC230 Class, PG607, MZ626 and FC100. The name of the model was concealed to safeguard the integrity of the manufacturer.

\subsection{Parameters Used}

The ages and kilometers travel, time of occurrence and the cost of repair data of the serviced vehicles were collected. The mean vehicular ages and/or distance covered were obtained across all brands throughout the periods of investigation. The data obtained from the maintenance experts were used to calculate crankshaft failure rate and cost consequence/the maintenance shop used are in operation for so many years ago (30 years). The model parameters used includes:

Age (A), Distance travel (S), Time of occurrence (Y)

\subsection{Other Parameters Measured/Predicted}

The parameters measured include: Failure rate (wear/day) and Failure consequence (The equations for calculating the failure rate and the failure consequence are given as follows:

$$
\begin{aligned}
& \mathrm{R}(\mathrm{t})=\mathrm{f}(\text { Age })+\mathrm{f}(\mathrm{S})+\mathrm{f}(\mathrm{Y}) \\
& \beta^{[\mathrm{II}]}(\mathrm{f})=\mathrm{f}(\text { Age })+\mathrm{f}(\mathrm{S})+\mathrm{f}(\mathrm{Y})
\end{aligned}
$$

where:

$\mathrm{R}(\mathrm{t})$, failure rate

$\beta^{(\sharp)}(\mathrm{f})$, failure consequence

$\mathrm{f}$ (Age), vehicle age before failure (A) in year

$\mathrm{f}(\mathrm{S})$, vehicle distance travelled before failure $(S)$

$f(Y)$, time of occurrence of the failure (in year)

\subsection{Computer Software Development}

This comprises:

Algorithm / Flowchart,

Using Microsoft Visual C\# computer Language (Front end or engine) and

Microsoft Structured Query Language (SQL) Server Compact Edition (Back end or engine). The outputs of predicted failure rate were generated for possible decisions: replace/reconditioning or do not, and output sample (validation).

\subsection{Software Validation}

Paired T-test Statistical analysis was used to check the level of significant difference between the mean of actual values obtained and mean of predicated values determined. $5 \%$ level of significant difference was used to check if there is significant difference between the mean of the variables.

\subsection{Data Collected for Vehicular Crankshafts from Mechanic Workshop A, B and C}

Three (3) workshops A, B and C was visited to collect the required data for each 
vehicular types selected for analysis in this research. Questionnairing forms were prepared to collect data required for this research and responds from various interviews granted to the experts was also recorded. The tables element consist of number of crankshaft reported for repair per day, cost of repair per crankshaft for re-grind and interchange or replacement, average distance travel before failure per crankshaft and average age of crankshaft per one.

\subsection{Computer Software Development}

A computer software program was developed to facilitate among the parameters namely failure rate $\mathrm{R}(\mathrm{t})$, failure consequence $B^{(\mathrm{N})}(f)$, age $(\mathrm{A})$, distance travelled $(\mathrm{K})$ and time $(\mathrm{Y})$ according to Equation (1) and (2). Flowchart/algorithm was developed for rapid implementation by maintenance practitioner using Microsoft Visual C\# as computer language. Figure 2 shows the flowchart for the computer software in line with the algorithm. Data were collected in three (3) workshops on age, distance travelled before failure, number of vehicle reported repair per day, cost of repairs per one and the year under review as input parameters for the developed software.

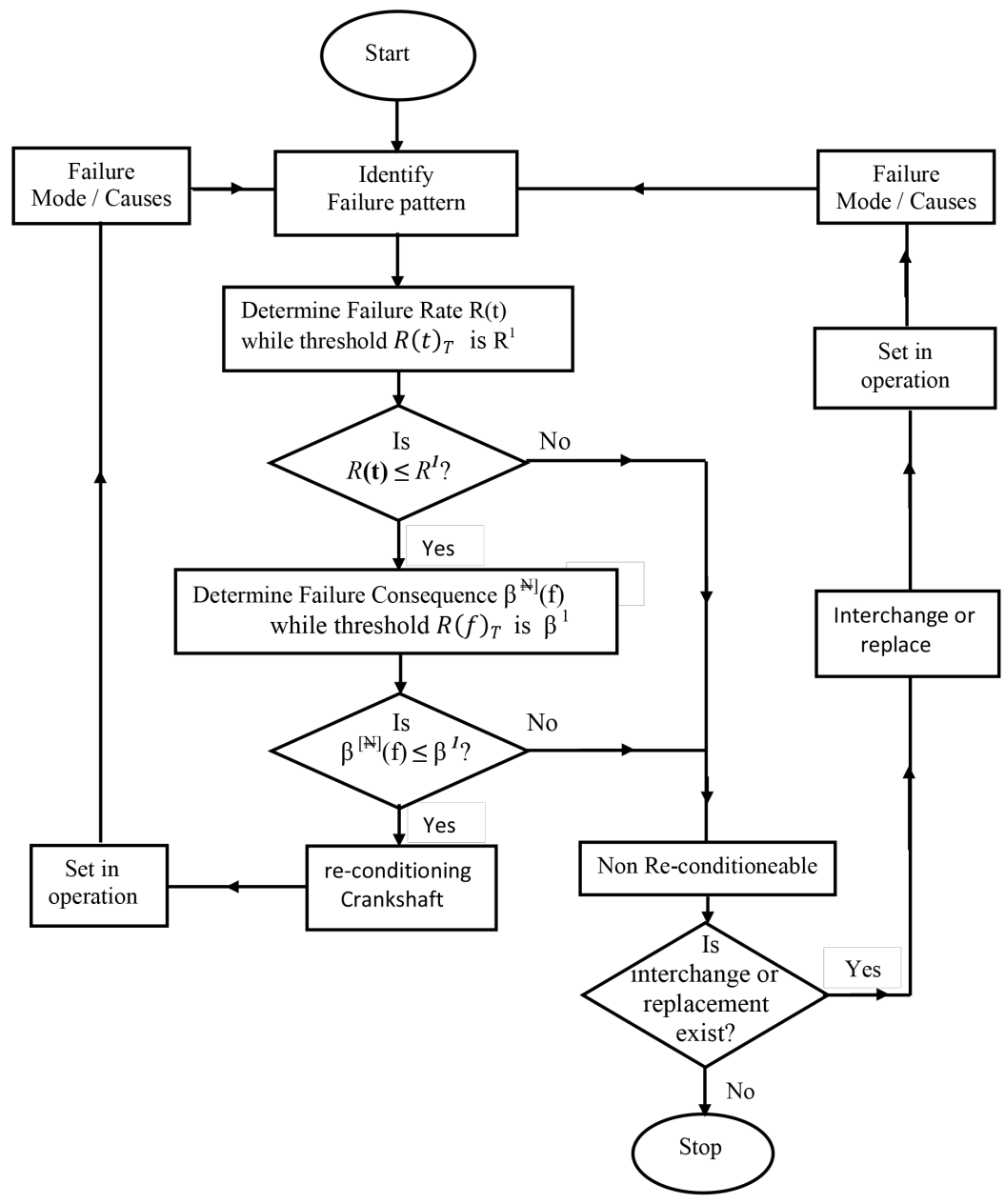

Figure 2. Flowchart for system software development. 
With respect to threshold values Equations (1) and (2) were used to predict Age and Distance travel of crankshaft from which proactive maintenance management based on crankshaft replacement or interchangeability were carried out using the following criteria:

If $\mathrm{R}(\mathrm{t})>\mathrm{R}(\mathrm{t})_{\mathrm{T}}$ replace or interchange crankshaft, otherwise reconditioning process continue (or) if $B^{(*)}(f)>R(f)_{T}$ replace or interchange crankshaft, otherwise reconditioning process continue.

where:

$$
\begin{aligned}
& R(t)_{T} \text {, threshold failure rate } \\
& R(f)_{T} \text {, threshold failure consequence }
\end{aligned}
$$

\subsection{Flowchart for System Software Development}

Flowchart of the system starts from identification of failures in vehicular crankshaft with respect to the age, distance travelled, and time of occurrence from which failure pattern was identified using relationship among the stated factors. Failure modes/causes that related to the failure patterns were noted. The data collected served as input into the developed computer software program. It has ability to rapidly give output results related to failure rate and consequence as determined by the model. The generated data helped to analyse the interplay among the various factors to arrive at a tangible conclusion.

\section{Result and Discussions}

\subsection{Software Algorithm}

Microsoft Visual C\# programme language is to develop the software algorithm (Crankshaft Failure Analysis) as in Figure 3. Starting with selection of vehicular brand/model, (TC) crankshaft was first selected, its crankshaft age is 10 years, distance travel is $200,000 \mathrm{~km}$ and time of occurrence is 8 years. The failure rate threshold and failure consequence threshold obtained as 13 wear/day, $\$ 3500$ respectively. The output result obtained from the software showed that the failure rate and failure consequence values 11.4272 wear/day and $\$ 1373.64$ respectively. Therefore, since the output results obtained for both failure rate and failure consequence are less than their threshold values, then crankshaft re-grind recondition process will be established. The results of the software and manually calculated failure rate and failure consequence values were found to be similar. This proved that the software developed is reliable. Besides it is faster ( 7 times faster than manual method of computation). Manual method of computation took 15 minutes 29 seconds while the computer processing and data loading time took only 2 minutes 5 seconds. The developed software (Figure 3 ) enables sensitivity analysis of the failure process at varying age, distance travel or time of failure occurrences, one at a time where other value are kept constant. The results obtained are discussed in the following section. 


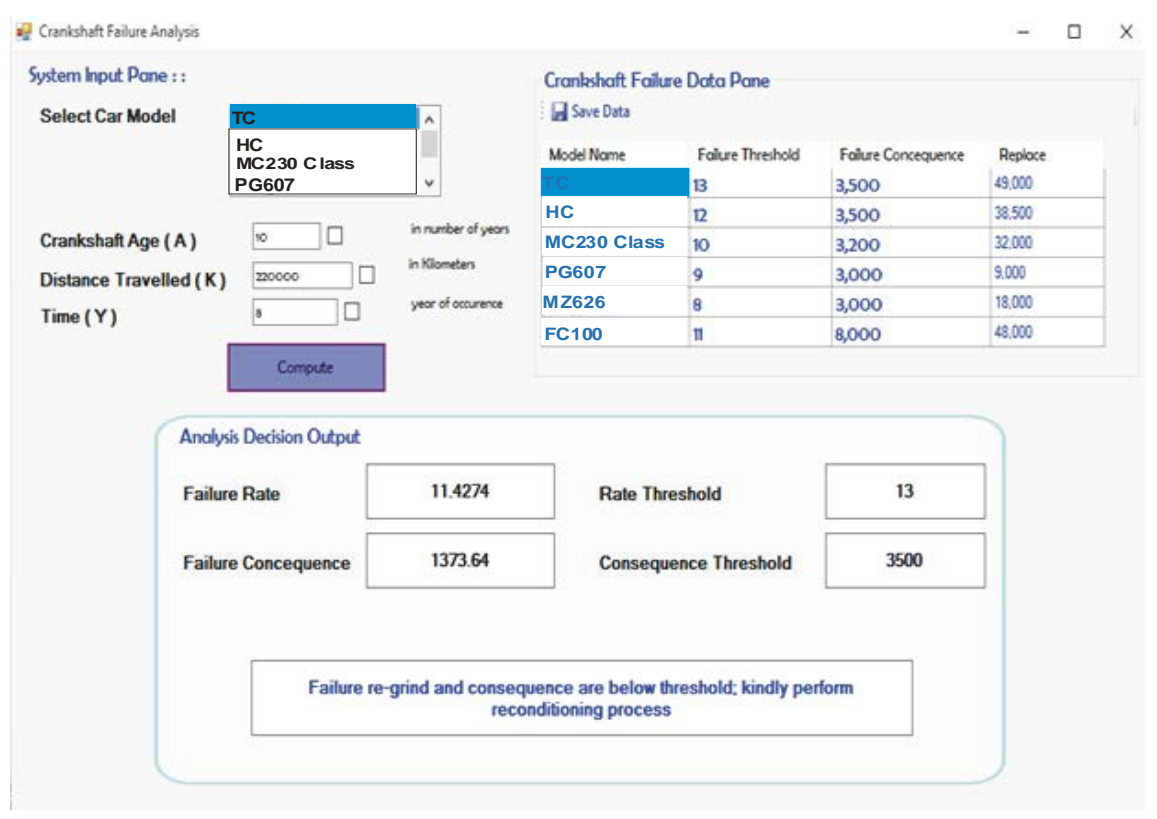

Figure 3. Software algorithm of crankshaft failure analysis interface.

\subsection{Sensitivity of Crankshaft Failure Analysis for Workshop A}

Sensitivity analysis was carried out using software development under six (6) scenarios. The results obtained are discussed in the following section.

Scenario 1: The values of Failure rate obtained from Computer Software result were plotted against Time of occurrence (in year) for vehicular brands at constant distance and age $(100,000 \mathrm{~km} ; 5$ years) were considered. MC230 Class gave the best result, its failure rate was difficult to identify followed by FC100 that it's failure rate was not observed not until after 3 years and increased to 2.285 wear/day at the time of 10 years. MZ626 came third with wear rate of 3.859 wear/day at the first year and increased slightly to 4.948 wear/day at time of 10 years. The fourth is PG607 that had a very high rate of wear of 11.218 wear/day but decreased rapidly to 2.245 wear/day at the 10 years' time of occurrence. HC was the fifth with initial wear rate of 7823 wear/day and increased slightly to11.936 wear/day wear rate while TC came last under this scenario. Its initial wear rate in the first year was the greatest which is 13.881 wear/hr and it increased from this high value to 18.939 wear/day at the time of 10 years. Figure 4 shows the failure rate analysis results consideration Time of occurrence (in year) of the various vehicular crankshaft brands considered

Scenario 2: The results of the sensitivity analysis of Failure consequence plotted against Time of occurrence (in year) for vehicular brands at constant distance and Age (100,000 km; 5 years). It shows that HC had the highest Failure consequence which increased from $\$ 618.272$ at the first year of time of occurrence to $¥ 2,488.67$ at the 10 years followed by Peugeot 607 that its failure consequence increased with the time of occurrence (in year) at constant distance and Age. For MC Class, TC and MZ 626, they maintain zero failure consequence up till 2 years later increased from zero to $\$ 1779.353$, $\$ 1493.874$ and $\$ 2,488.67$ 


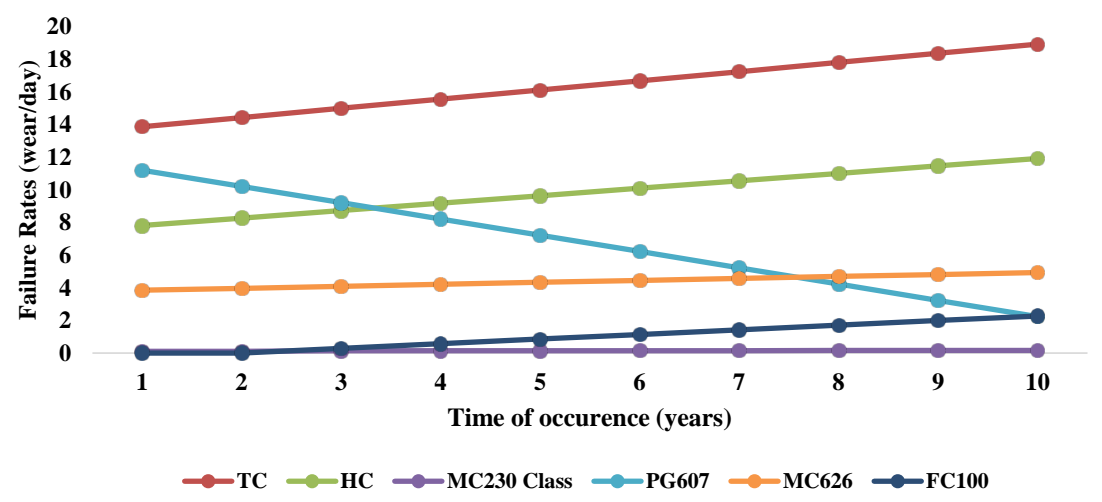

Figure 4. Graph of Failure rate with Time of occurrence for vehicular brands at constant distance and Age (100,000 km; 5 years).

respectively. FC100 gave the least values of failure consequence and therefore the best results compared to other vehicular crankshaft brands under consideration. A zero failure consequence was obtained up till the fifth years before it increased to $\$ 1660$ at time of 10 years. These analyses are shown in Figure 5, the failure consequence analysis results with Time of occurrence (in year) of the various vehicular crankshaft brands considered. This sensitivity analysis is shown in Figure 5.

Scenario 3: Results of the sensitivity analysis of crankshaft failure rate obtained from the software developed was plotted against Age (in year) starting from the first year to the tenth year under investigation for vehicular brands at constant distance travelled and time of occurrence (in year) $(100,000 \mathrm{~km} ; 8$ years). Considering this scenario, it shows that the Failure rate of crankshaft brands of MC 230 Class gave the best result, its failure rate was the least, its ranges from 0.068 to 0.99 wear/day followed by FC100 that its failure rate decreased from 2.611 to 0.592 wear/day at the time of 10 years. Mazda 636 came third with wear rate of 2.41 wear/day at the first year and increased slightly to 7.576 wear/day at time of 10 years. The fourth is PG 607 that had a high rate of wear of 7.355 wear/day but decreased rapidly to 0.344 wear/day at the 10 years' time of occurrence. HC was the fifth with initial wear rate of 10.566 wear/day and increased slightly to11.592 wear/day wear rate while TC came last under this scenario. Its initial wear rate in the first year was the greatest which is 19.903 wear/day and decreased very slightly to 15.205 wear/day at the time of 10 years. This sensitivity analysis is shown in Figure 6.

Scenario 4: The results of Failure consequence obtained from software developed was plotted against Age (in year) starting from the first year to the tenth year under investigation for vehicular brands at constant distance and time of occurrence (in year); $(100,000 \mathrm{~km} ; 8$ years). It shows that HC had the highest Failure consequence which increased from $\$ 1680.034$ at the first year of time of occurrence to 2564.266 at the 10 years followed by PG 607 that its failure consequence decreased very slightly with the time of occurrence (in year) at constant distance and Age from $\$ 1817.909$ at the first year of time of occurrence to 


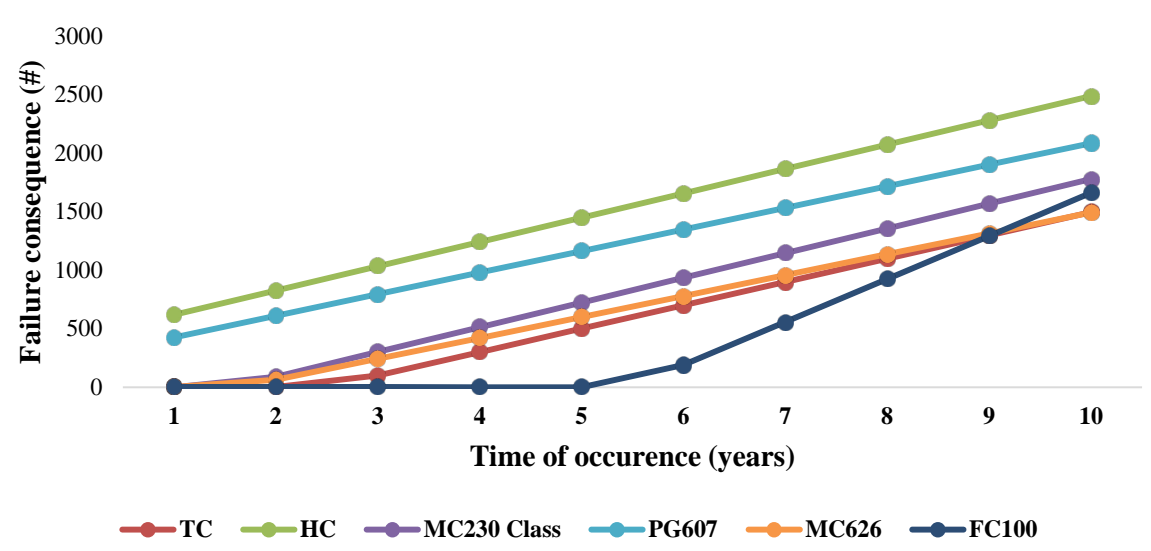

Figure 5. Graph of Failure consequence with Time of occurrence for vehicular brands at constant distance and Age (100,000 km; 5 years).

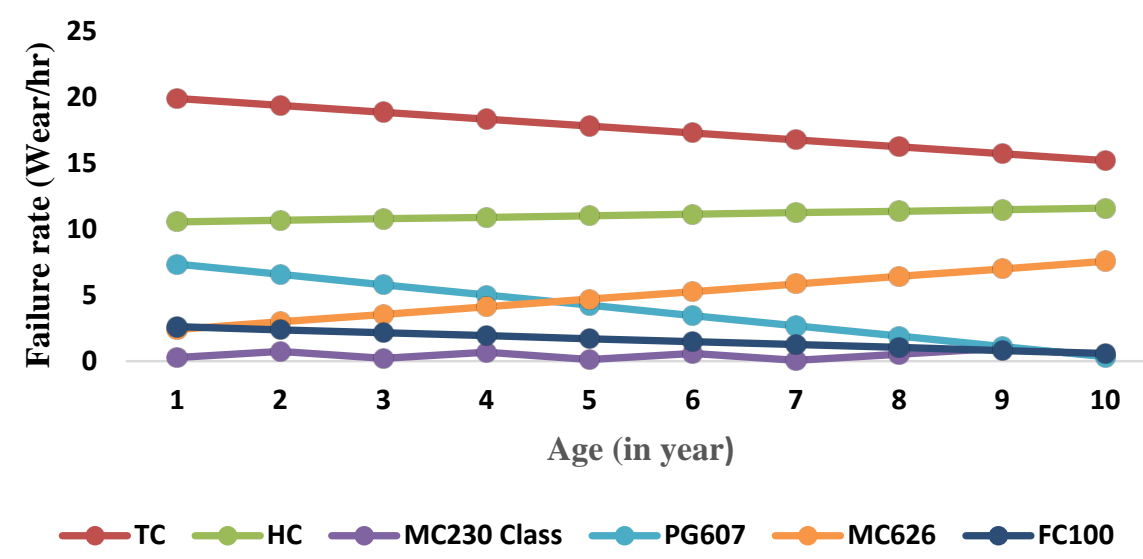

Figure 6. Graph of Failure rate with Age for vehicular brands at constant distance and Time of occurrence (in year) $(100,000 \mathrm{~km} ; 8$ years) of Workshop A.

1591.289 at the 10 years. The next was MC230 Class, its failure consequence deceased from 1418.695 at the first year of time of occurrence to 1279.915 at the 10 years. But for TC and MZ 626, both maintain slightly increased in failure consequences from $\$ 1069.371$, $\$ 845.284$ to $\$ 1113.64$, $\$ 1,499.494$ respectively. FC 100 gave the least values of failure consequence and therefore the best results. It gave very low failure consequence ( $\$ 0.03)$ in the first 2 years before increased rapidly to 2281.453 at the 10 years. This sensitivity analysis is shown in Figure 7 .

Scenario 5: The results of failure rate sensitivity analysis obtained from software developed was plotted against distance travelled (in kilometer) starting from 50,000 km to 140,000 km under investigation for at constant Age and time of occurrence (in years) [10 years; 5 years]. MC230 Class gave the best result, its failure rate was difficult to notify. It was followed by PG607 and FC100, both had the same level of failure rate throughout the distance covered under consideration. Their failure rate decreases from 3.9835 wear/day, 4.1375 wear/day at $50,000 \mathrm{~km}$ to 0.8542 wear/day, 0.8029 wear/day at $140,000 \mathrm{~km}$. These three vehicular brands maintain the same failure rate at $140,000 \mathrm{~km}$. MZ636 came fourth 
with wear rate of 5.748 wear/day at the $50,000 \mathrm{~km}$ and decreased slightly to 4.308 wear/day at time of $140,000 \mathrm{~km}$. HC was the fifth with initial wear rate of 8.809 wear/day and increased slightly to14.438 wear/day wear rate while TC came last under this scenario. Its initial wear rate in the first $50,000 \mathrm{~km}$ was the highest which is 20.513 wear/day and it decreased from this high value to 17.679 wear/day at distance of 140,000 km. This sensitivity analysis is shown in Figure 8.

Scenario 6: The results of sensitivity analysis of the crankshaft failure consequence was plotted against distance travelled (in kilometer) starting from 50,000 $\mathrm{km}$ to $140,000 \mathrm{~km}$ under investigation for vehicular brands at constant Age and time of occurrence (in years) [10 years; 5 years]. From Figure 9 it shows that the Failure consequence of crankshaft brands of $\mathrm{HC}$ has the highest failure consequence followed by PG 607 both decreased very slightly from $\$ 2938.67$ and $\$ 2938.67$ at $50,000 \mathrm{Km}$ to $\$ 2128.67$ and $\$ 1926.085$ at $140,000 \mathrm{~km}$ respectively. However, MC 230 Class vehicular crankshafts increased very slightly from $\$ 1629.353$ at 50,000 km to 1899.353 at $140,000 \mathrm{~km}$. Also, TC and MZ 626

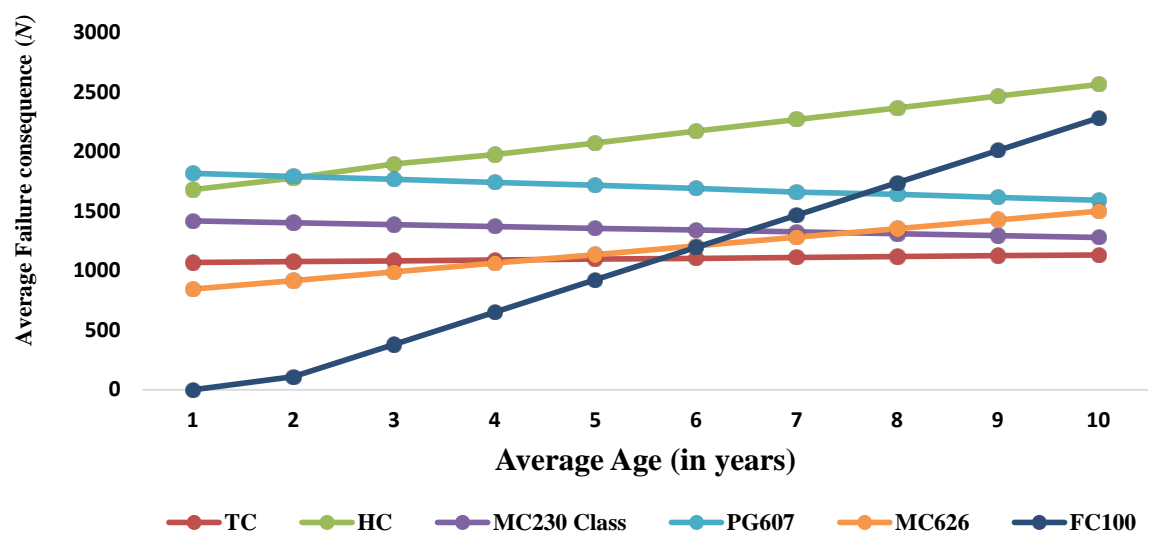

Figure 7. Graph of Failure consequence with Age for vehicular brands at constant distance and Time of occurrence (in year) $(100,000 \mathrm{~km} ; 8$ years) of Workshop A.

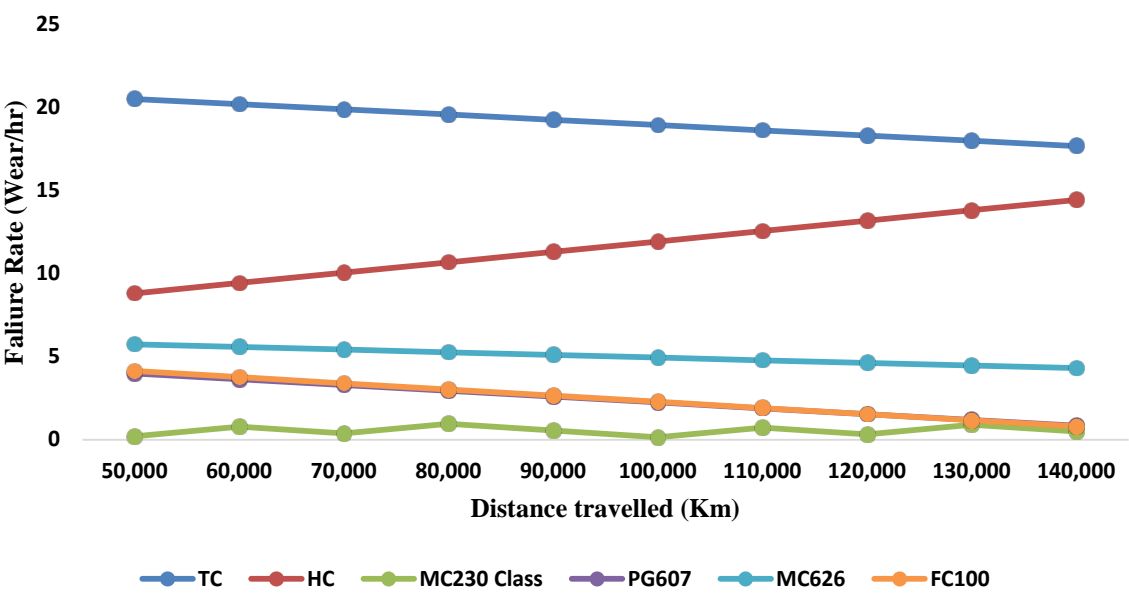

Figure 8. Graph of Failure rate with Distance travelled for vehicular brands at constant Age and Time of occurrence in years (10 years; 5 years) of Workshop A. 


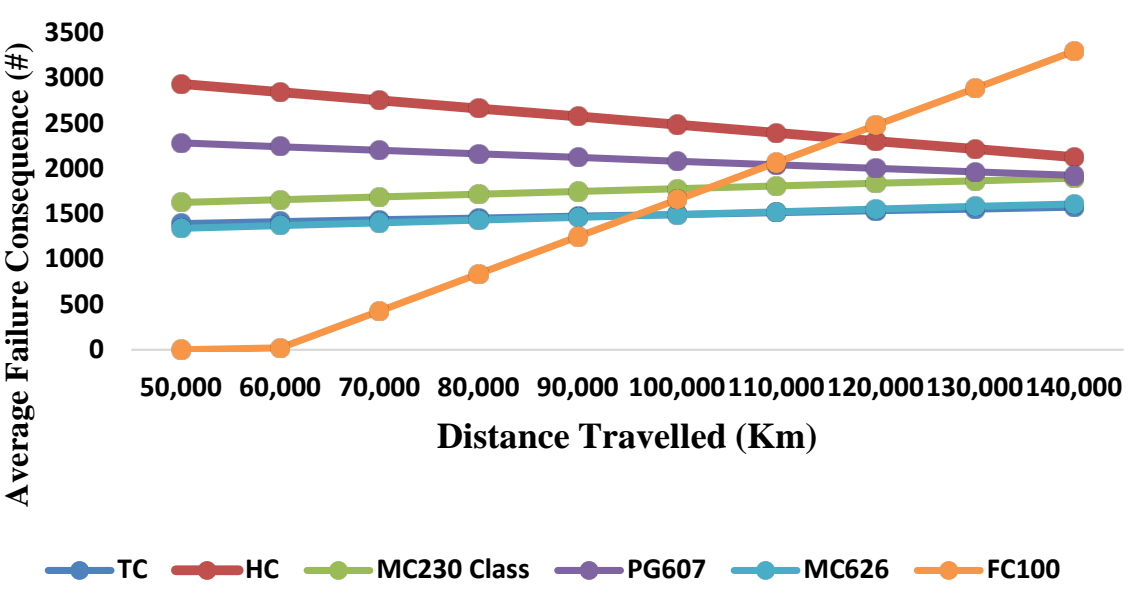

Figure 9. Graph of Failure consequence with Distance travelled for vehicular brands at constant Age and Time of occurrence in year (10 years; 5 years) of Workshop A.

maintain nearly the same failure consequence through the distance covered from $50,000 \mathrm{~km}$ to $140,000 \mathrm{~km}$ according to the graph. The last was FC 100 that had a zero ( cost of failure consequence starting from $50,000 \mathrm{~km}$ to $60,000 \mathrm{~km}$ before it's rapidly increased to $\$ 3300.292$ at $140,000 \mathrm{~km}$ distance covered.

In general, MC230 Class has the low failure rate followed by FC100 and PG607 vehicular crankshafts. TC has the highest wear/failure rate therefore took last position followed by HC. However TC generated the high value (failure consequence) for the workshop which is $\$ 49,000$ per day followed by FC100 ( $\$ 48,000)$ and HC ( $\$ 48,000)$.

\subsection{Paired t-Test for Failure Rate/Failure Consequence}

Paired T-test Statistical analysis was used to check the level of significant different between the actual values and predicated values.

Hypothesis:

$\mathrm{H}_{0}: \mu_{1}=\mu_{2}$

$\mathrm{H}_{1}: \mu_{1} \neq \mu_{2}$

Decision rule: reject $\mathrm{H} 0$ if $\mathrm{p}_{\text {calculated }}<\mathrm{p}$-value

Inference: $\mathrm{p}_{\text {cal }}=1.000$, $\mathrm{p}$-value 0.05

since $\mathrm{p}_{\text {cal }}>\mathrm{p}$-value there is no enough evidence to reject $\mathrm{H}_{0}$. We conclude that there is no significant difference between the actual values and predicted values. The validation of the developed computer software program shown that the software can adequately predict the failure rate/consequence of the crankshaft. The actual values and predicated values obtained from Regression model analysis was shown in Table 1.

\section{Conclusion}

Ages and distance travel were used as major criteria that influence the failure rate of crankshaft at a normal condition. A Statistical Package for Social Science (SPSS) software was used to develop regression model that relates variables. A 
Table 1. Predicting values of failure rate and failure consequence for 16 years.

\begin{tabular}{|c|c|c|c|c|}
\hline \multirow{2}{*}{ No } & \multicolumn{2}{|c|}{ Failure Rate } & \multicolumn{2}{|c|}{ Failure Consequence } \\
\hline & Actual values & Predicted values & Actual values & Predicted values \\
\hline 2001 & 4 & 6.581 & 300.000 & 34.559 \\
\hline 2002 & 6 & 7.157 & 400.000 & 234.118 \\
\hline 2003 & 8 & 7.748 & 500.000 & 433.677 \\
\hline 2004 & 9 & 8.339 & 600.000 & 633.236 \\
\hline 2005 & 13 & 8.930 & 600.000 & 832.795 \\
\hline 2006 & 17 & 9.521 & 1000.000 & 1032.354 \\
\hline 2007 & 6 & 10.112 & 1200.000 & 1231.913 \\
\hline 2008 & 9 & 10.703 & 1200.000 & 1431.427 \\
\hline 2009 & 10 & 11.294 & 1500.000 & 1631.031 \\
\hline 2010 & 12 & 11.885 & 2000.000 & 1830.590 \\
\hline 2011 & 12 & 12.476 & 2000.000 & 2030.149 \\
\hline 2012 & 10 & 13.067 & 2000.000 & 2229.708 \\
\hline 2013 & 12 & 13.658 & 2200.000 & 2429.267 \\
\hline 2014 & 20 & 14.249 & 2500.000 & 2628.826 \\
\hline 2015 & 16 & 14.840 & 3000.000 & 2828.385 \\
\hline 2016 & 14 & 15.431 & 3500.000 & 3027.944 \\
\hline
\end{tabular}

software for the individual brand/model of crankshaft was developed to determine/predict the interaction among the parameters namely, age, distance travel and time of occurrence. Flowchart/algorithm was developed for the input parameters using Microsoft Visual C\# as computer language to predict the likely crankshaft failure rate and consequence. The validation of the developed computer software program was tested and established using paired t-test statistical analysis that shows that there is no significant difference between the mean of actual data (failure rate/failure consequence) and the predicted data using 5\% level of significant. This confirmed that the model is reliable for prediction. The findings from this study on crankshafts failure rate and failure consequence will help maintenance practitioners in the choice of the best crankshaft to procure in terms of low failure rate and low failure consequence. Further study is expected to cover crankshafts of more vehicle brands with extension to operational conditions and materials investigation as related to crankshafts failure. The outcome will serve as indicator on which the sensitivity of the process employed in this study will be determined.

\section{References}

[1] Akinola, A.O. and Ogedengbe, T.I. (2003) Basic Automobile Technology. 2nd Edition, Olajuyin Printers Ltd., Nigeria.

[2] Kareem, B. (2015) Evaluation of Failures in Mechanical Crankshafts of Automobile 
based on Expert Opinion. Journal of Case Studies in Engineering Failure Analysis, 3, 25-33. https://doi.org/10.1016/j.csefa.2014.11.001

[3] Ajieogwu, J.O. (2004) Need for Continuous Professional Training as a Means of Promoting Conference of Automotive Mechanics. A paper presented at NATA $A u^{-}$ to-Technical Workshop and Exhibition 2003, Ondo City.

[4] Pratik, K. and Manish, D.P. (2015) Analyzing and Identifying Various Approaches for Crankshaft Failures. Journal of Multidisciplinary Engineering Science and Technology (JMEST), 2, 76-77.

[5] Heisfer, H. (2005) Advanced Engine Technology. 3rd Edition, Ssheshan Pugazhendhi, London, 87-92. http://www.bh.com

[6] Kareem, B. (2007) A Survey of Failure in Mechanical Crankshafts of Automobile. Journal of Engineering Applied Science, 2, 1165-1168.

[7] Fonte, M., Li, B., Reis, L. and Freitas, M. (2013) Crankshaft Failure Analysis of a Motor Vehicle. Journal of Engineering Failure Analysis, 35, 147-152.

https://doi.org/10.1016/j.engfailanal.2013.01.016

[8] Ahmed, K., Nader, H., Farhad, R. and Hassine, F.A. (2016) On the Assessment of Train Crankshafts Fatigue Life Based on LCF Tests and 2D-FE Evaluation of J-Integral. Journal of Case Studies in Engineering Failure Analysis, 66, 354-654.

[9] Amit, P., Gajanan, D. and Amol, K. (2014) Crankshaft Failure Due to Fatigue. International Journal of Mechanical Engineering and Robotics Research (IJMERR), 3, No. 1.

[10] Silva, F.S (2003) Analysis of Vehicle Crankshaft Failure. Engineering Failure Analysis, 10, 605-616. https://doi.org/10.1016/S1350-6307(03)00024-4

[11] Becerra, J.A., Jimenez, F.J., Torres, M., Sanchez, D.T. and Carvajal, E. (2011) Failure Analysis of Reciprocating Compressor Crankshafts. Engineering Failure Analysis, 18, 735-746. https://doi.org/10.1016/j.engfailanal.2010.12.004

[12] Jiménez, E.F. (2009) Analysis of Diesel Generator Crankshaft Failure. Engineering Failure Analysis, 16, 2333-2341. https://doi.org/10.1016/j.engfailanal.2009.03.019

[13] Infante, V. (2013) Failure of Crankshaft of Aero-Engine: A Contribution for an Accident Investigation. Engineering Failure Analysis, 35, 286-293. https://doi.org/10.1016/j.engfailanal.2013.02.002

[14] Nadolny, K. (2012) The Method of Assessment of the Grinding Wheel Cutting Ability to the Plunge Grinding. Central European Journal of Engineering, 2, 399-409. https://doi.org/10.2478/s13531-012-0005-5

[15] Colin, R.F. (2015) Internal Combustion Engine Applied Thermosciences. 3rd Edition, John Wiley \& Sons, Hoboken.

[16] Katari, A. (2011) Fatigue Fracture Expertise of Train Engine Crankshafts. Engineering Failure Analysis, 18, 1085-1093. https://doi.org/10.1016/j.engfailanal.2011.02.007

[17] Bhaumik, S.K. (2002) Fatigue Fracture of Crankshaft of an Aircraft Engine. Engineering Failure Analysis, 9, 255-263. https://doi.org/10.1016/S1350-6307(01)00022-X

[18] Pandey, R.K. (2003) Failure of Diesel Engine Crankshafts. Engineering Failure Analysis, 10, 165-175. https://doi.org/10.1016/S1350-6307(02)00053-5

[19] Chien, W.Y. (2005) Fatigue Analysis of Crankshaft Sections under Bending with Consideration of Residual Stresses. International Journal of Fatigue, 27, 1-19. https://doi.org/10.1016/j.ijfatigue.2004.06.009 
[20] Wang, C. (2005) Analysis of an Unusual Crankshaft Failure. Engineering Failure Analysis, 12, 465-473. https://doi.org/10.1016/j.engfailanal.2004.01.006

[21] Xuanyang, L. (2007) Simulation on the Motion of Crankshaft with a Slant Crack in Crankpin. Mechanical Systems and Signal Processing, 21, 502-513. https://doi.org/10.1016/j.ymssp.2005.08.007

[22] Bayrakceken, H. (2007) Failures of Single Cylinder Diesel Engines Crank Shafts. Engineering Failure Analysis, 14, 725-730. https://doi.org/10.1016/j.engfailanal.2006.01.006

[23] Fonte, M., Infante, V., Freitas, M. and Reis, L. (2016) Failure Mode Analysis of Two Diesel Engine Crankshafts. 15th Portuguese Conference on Fracture, 10-12 February 2016, Vol. 1, 1049-001.

[24] Çevik, G. and Gurbuz, R. (2013) Evaluation of Fatigue Performance of a Fillet Rolled Diesel Engine Crankshaft. Engineering Failure Analysis, 27, 250-261. https://doi.org/10.1016/j.engfailanal.2012.07.026

[25] Jung, D.H. (2009) Reliability Prediction of Fatigue Life of Crankshaft. Journal of Mechanical Science Technology, No. 23, 1071-1074.

[26] Ndirpaya, B.Y. (2011) Appraisers and Cost Engineers of Motor Vehicle Valuation. Institute of Appraisers and Cost Engineers, Abuja, 6-11. 